\title{
Conceptual understanding of 8th grade students based on big ideas: The case of measurement
}

\author{
Özlem Kalaycı Eyeoğlư1, Burçin Gökkurt Özdemir² and Ulvi Eyeoğlu ${ }^{3}$ \\ ${ }^{1}$ Ministry of National Education, Bartın, Turkey (ORCID: 0000-0002-1705-7519) \\ 2Bartin University, Faculty of Education, Turkey (ORCID: 0000-0002-1551-0113) \\ ${ }^{3}$ Ministry of National Education, Bartm, Turkey (ORCID: 0000-0001-6550-9148)
}

\begin{abstract}
This study aims to examine the conceptual understanding of middle-school 8th graders on measurement based on big ideas. To this aim, a case study was carried out with six students from a state middle school. The data were collected through semi-structured interviews with the instrument developed by the researchers and consisting of seven open-ended questions. Both descriptive and content analysis were performed to analyze the data. Descriptive analyses were conducted considering the framework of two big ideas in the area of measurement identified by the NCTM (2000). Content analysis using NVivo was employed in analysing the audio-recorded interviews and written responses. The results revealed students had a limited understanding of measurement. It was also determined that the majority of the students made dimensional estimations, showed a rote-based approach in calculating the perimeter, area and volume, and had difficulties in making sense of these concepts. In addition, the understanding of students regarding the volume was found to be limited to interior volume. Finally, some recommendations were made to develop understanding of measurement of students.
\end{abstract}

Keywords: Geometry teaching; Learning area of measurement; Big idea; Middle school students

Article History: Submitted 13 April 2021; Revised 8 October 2021; Published online 2 November 2021

\section{Introduction}

Measurement and measurement-related practices, which are an essential part of the mathematics curriculum, are closely linked to the sub-learning areas of mathematics such as Numbers (counting), Place Value (the metric system in measurement based on the decimal number system), Algebra (measurement providing the data to reveal the functional relationship and generalization), and Fractions (Lee, 2012; National Council of Teachers of Mathematics [NCTM], 2000). From this standpoint, the difficulties students experience in measurement perhaps negatively affect their success in other learning areas of mathematics. Indeed, research that support this view (Gough, 2008; Kenney \& Kouba, 1997; Kidman \& Cooper, 1997; Kim, et. al., 2019; Moreira \& Contente, 1997) showed that students fail to comprehend concepts such as circumference, area and volume due to the difficulties they experience in constructing the concept of measurement, make measurements based on the formulas they memorize, and cannot develop a certain understanding of measurement. Similarly, international studies such as Trends in International Mathematics and

Address of Corresponding Author

Burçin Gökkurt Özdemir, PhD, Bartın University, Faculty of Education, Department of Mathematics Education, 74110, Bartın, Turkey.

$\triangle$ gokkurtburcin@gmail.com

How to cite: Kalaycı-Eyeoğlu, Ö., Gökkurt-Özdemir, B. \& Eyeoğlu, U. (2021). Conceptual understanding of 8th grade students based on big ideas: The case of measurement. Journal of Pedagogical Research, 5(4), 19-42. https:/ /dx.doi.org/10.33902/JPR.2021472786 
Science Study [TIMSS] and National Assessment of Educational Progress [NAEP] indicated that students have the hardest time with measurement among other subjects in the curriculum (cited in Lee, 2012; Thompson \& Preston, 2004). Besides, NCTM (2000) emphasizes the relation of the concept of measurement with daily life. Therefore, it is necessary to address measurement (Van de Walle, Karp \& Ray-Willams, 2014) conceptually in order to identify these relationships.

Big Ideas are very useful in dealing with measurement conceptually. Indeed, the importance of focusing on "short, clear, key ideas and strategies", that is, on big ideas, has been widely recognized in geometry and measurement learning, especially in countries such as the USA, the Netherlands, Singapore and Australia (Charles, 2005; Siemon, Bleckly \& Neal, 2012). Studies on the concept of measurement considering big ideas (Charles \& Carmel, 2005; NCTM, 2000) reported that students should learn the measurable qualities (length, area, weight, volume, etc.) and comprehend how the unit of measurement affects measurement and understand how to use formula in measurement, starting from pre-school level to the 8th grade level. Thus, understanding of what a measurable attribute is and familiarity with the working principle of the measurement units are important for the correct and proper use of measurement tools and the development of the concept of measurement. However, developing measurement concepts and skills in children from an early age is not as easy as it seems (Kayhan \& Argün, 2011; Lee, 2012). For that reason, it is pivotal to determine the students' prior knowledge of the concept of measurement, their knowledge structuring processes (Marks, 1990; NCTM, 2000), their understanding of measurement on basic geometric shapes and concepts, and their perspectives on measurement for an effective geometry teaching. These being said, the purpose of this study is to examine the conceptual understanding of the middle school 8th grade students based on big ideas. Further, it seeks to identify the measurement approach of these students regarding the properties of two-dimensional shapes and three-dimensional geometric bodies based on big ideas. Insights into the conceptual understanding of the students on measurement would potentially help providing teachers and researchers with a mental frame of reference for organizing educational activities around certain ideas in measurement and teaching process. This study then offers the following theoretical foundations of geometry and measurement for a better interpretation of the students' approach to measurement.

\subsection{Measurement and Big Ideas in Measurement}

In the broadest sense, measurement is the assignment of a numerical value to the attribute of an object (such as the length of a pencil) (NCTM, 2000, p. 44). From this standpoint, to measure something, it is necessary to first understand what a measurable attribute is, then to select the unit of measurement with that attribute (Common Core State Standards for Mathematics, Common Core State Standards Initiative [CCSSI], 2010). However, this needs to be performed based on measurement-related experiences. Therefore, the best way to develop a deep understanding of measurement is to provide students with opportunities to make measurements in real life using appropriate measurement tools and measurement units and to check whether the measurement results they obtain are reasonable or not (Lee, 2012). Yet, to do so, it is essential to make sense of some basic concepts in measurement and to address these concepts considering their cause and effect relationship (Battista, 2007). For this reason, discussion on measurement based on big ideas is of great importance. Charles and Carmel (2005, p. 10) expressed "big ideas" as a "coherent set of ideas" or a "coherent whole" that encourages a deep understanding of the discipline, allows for the transfer of what has been learned, reduces the amount of information to be remembered and facilitates retention. That is to say, big ideas are defined as "the central, organizing ideas of mathematics principles that define mathematical order" (Schifter \& Fosnot, 1993, p.35). In this sense, comprehension of big ideas in measurement would allow for developing a deep understanding of measurement (Hiebert \& Carpenter, 1992, p.67). In fact, NCTM (2000) deals with the learning area of measurement within the framework of two big ideas. The first big idea is to "understand the measurable attributes of objects as well as unit in measurement and measurement processes" and the 
second one is to "apply formulas, appropriate measurement techniques and measurement tools to determine measurements". Below are the theoretical foundations of these two big ideas:

\subsubsection{Big Idea 1) Understand the measurable attributes of objects as well as unit in measurement and measurement processes}

Regarding this big idea, NCTM (2000) discusses the following aspects: determining the attribute to be measured; recognizing the attributes of two-dimensional geometric shapes and three-dimensional objects such as volume, length, area and weight; using non-standard and standard measurement units; comparing and ordering measurements. NCTM highlights comparing, finding approximate equivalents and the concept of equivalence between different measurement units in the area of measurement for each grade level. These aspects are explained under their respective headings as follows:

Measurable attribute: To make a measurement, it is first necessary to understand what a measurable attribute is and then to select the unit of measurement with that attribute. For example, line segments have length while plane regions have area and physical objects have mass, which are measurable attributes (NCTM, 2005; p.44). While selecting the unit of measurement, students need to feel that they require different units to measure different attributes (e.g. length is measured in linear measures while area is measured in unit squares). It is further significant to determine the appropriate unit of measurement. For example, when the length of a football field is measured in centimeters, the result may be difficult to interpret and use. For that reason, students need to understand the role of units in measurement by the end of their elementary school years. Besides, using non-standard and standard units is prerequisite in measurement. Because using non-standard units (span, stroke, pace, etc.) makes it easier to focus on the measured attribute. For this reason, it is significant for the comprehension of measurement that students benefit from pace, paperclip to measure lengths, use square tiles and checkered papers to measure area and utilize glass to measure volume.

Equivalence: This is an important big idea that involves expressing measurement results using different units in equivalent ways. Equivalence means that different representations emphasize different characteristics (Tout \& Spithill, 2015). For example, the number 64 represents a square with a side length of $8 \mathrm{~cm}$ when expressed as $8^{2}$ and represents a cube with a side of $4 \mathrm{~cm}$ when expressed as $4^{3}$. From this standpoint, equivalence requires addressing the unit-size relationship. Besides, equivalence emphasizes the relationship between units. In this sense, students need to know the relationship between units such as the relationship between meter and centimeter. Regarding this big idea, asking students to "estimate the length of a rope first in meters and then in centimeters and compare the results" would make more sense compared to asking them "How many centimeters is two meters?"

Comparison: It involves comparing a selected attribute of an object with the relative values of measurement results such as length (longer/shorter, equal), area (larger/smaller, equal), mass/weight (heavier/lighter/equal) (Charles \& Carmel, 2005). Children in prekindergarten through grade 2 begin by comparing and ordering objects using language such as longer and shorter (NCTM, 2000). However, students at advanced grade levels may have difficulties in comparing area and volume (Sarama \& Clements, 2009; Van De Walle, et.al., 2014). For that reason, regarding this big idea, it is of great importance that area measurement involves creating different rectangles with the same area and volume measurement involves focusing on the concept of capacity, particularly at the primary school level.

Estimation/Approximate Value: Estimation, in the most general sense, is defined as quickly developing an idea about the quantity or size of something without actually counting or measuring it (Micklo, 1999). Related research (Hanson \& Hogan, 2000; Sowder, 1992) discuss estimation under three headings as measurement estimation, operational/computational estimation and dimensional estimation. Dimensional estimation refers to a rough estimation of the continuous quantities of objects such as length, area, volume and weight without using any measurement tool, through estimation strategies, whereas measurement estimation is estimating 
the number of objects with discrete quantities (Segovia \& Castro, 2009). Measurement estimation seeks to answer the question of "How many?" For example, to estimate how many handfuls of candies a jar can contain, one first needs to put a handful of candies in the jar and then to estimate how many handfuls of candies the jar contains based on the volume it occupies (Baroody \& Gatzke, 1991). Dimensional estimation embraces a similar reference point. For example, when estimating the size of a classroom, one refers to the size of another item $\mathrm{s} /$ he knows and uses it to estimate the number of that item corresponding to the size of the classroom. Operational/computation estimation is making reasonable guesses as approximate answers to arithmetic problems without making real calculations (Dowker, 1992). Understanding that all measurements are approximations is a difficult but important concept for students (NCTM, 2000). As estimation entails focusing on the measured quality and measurement process. In addition, the use of standard measurement units in estimation helps developing the concept of unit. For example, trying to estimate the height of a door in meters before measuring it is effective in developing an understanding of the size of the meter as a measurement unit.

Describing, Classifying, Analyzing: One of the big ideas put forward by NCTM (2000) is to express geometric shapes and the relationship between these shapes through measurement. As it is possible to determine what makes geometric shapes different or similar to each other by measuring the geometric properties of the shapes (Van de Walle, et. al., 2014). A reasoning based on the critical/non-critical properties of shapes was reported to be useful in the description of geometric shapes (Van Hiele, 1986). For example, for a triangle, the critical properties are a closed figure, three vertices and straight sides whereas the size of a triangle (small or large) is non-critical.

Similarly, for a perpendicular prism, polygonal bases, equal and parallel bases, rectangular lateral surfaces are critical properties while volume is a non-critical property (Gökkurt, 2014). Thus, the key purpose of geometry teaching should be to use critical properties in describing geometric shapes and forming concepts (Hershkowitz, 1990). As for the classification (categorization) of geometric shapes, the classification process is related to naming them, according to students. Indeed, students tend to assume that any geometric shape has only one name (Markman \& Watchtel, 1988). This assumption causes students to have a hard time in acknowledging that all quadrilaterals are trapezoidal, or understanding the hierarchical structure of geometric shapes. For example, students find it very difficult to identify sub-relationships that "all parallelograms are also trapezoidal, but not all trapezoids are parallelograms."

\subsubsection{Big Idea 2) Apply formulas, appropriate measurement techniques and measurement tools to determine measurements}

On this big idea, NCTM (2000) discusses the following aspects: making repeated measurements based on the units of the same size, using a common benchmark to make comparisons and estimations, and to develop strategies to determine the circumference, area, length and volume of irregular shapes and objects. Further, it involves the aspect of developing and using formulas to determine the area and volume. From this standpoint, measurement technique is defined as strategies employed in the form of counting, estimating, using formulas or tools to determine measurement results; measurement tools are described as tools for making measurements such as rulers, protractors, ropes, wooden sticks whereas formulas are defined as the relations with variables that yield the measurement result. As expected with this big idea, students should apply what they know about two-dimensional shapes in their work with three-dimensional objects. It emphasizes that while calculating a three-dimensional object, students need to associate the same object with its two-dimensional representation. For example, to develop the formula for the area of a parallelogram, triangle, or trapezoid, one may benefit from existing prior information on the area of a rectangle and come up with new formulas. Furthermore, it is pivotal to use standard (ruler, etc.) and non-standard (rope, wooden sticks, etc.) measuring tools (NCTM, 2000, p.46-47). 


\section{Method}

The method section presents the research model aimed to reveal students' conceptual understanding of measurement in the context of big ideas, as well as the data collection process.

\subsection{Research Design}

The study is a case study based on qualitative design, investigating the conceptual understanding of middle-school 8th graders on measurement based on big ideas. It portrays the existing conceptions of students without any intervention. The most important characteristic of the case study is that it enables us to focus on a special subject, group or situation (Yin, 2013). The unit of analysis is students' understanding of measurement. In a case study, a system with specific boundaries or a case is deeply discovered with the help of different data collection tools (McMillan \& Schumacher, 2010). In this study, audio recordings were taken together with the interview technique and observation notes were used.

\subsection{Participants}

This study was performed with a total of six students in the $8^{\text {th }}$ grade level, who study in a public school with a low socio-economic status located in the Black Sea region of Turkey, which is one of the seven geographical regions. It was carried out in the 2019-2020 academic year and the participants were selected through purposive sampling method (Creswell, 2013). In this process, the students who are in the $8^{\text {th }}$ grade level with good communication skills and thus can express themselves well were identified. The reason for selecting $8^{\text {th }}$ graders to take part in this study is the assumption that these students have a background, knowledge and experience about retrogeometry and measurement concepts. All participants were kept anonymous and abbreviated as $\mathrm{P}_{1}, \mathrm{P}_{2} \ldots \mathrm{P}_{6}$. Among the participants, $\mathrm{P}_{1}, \mathrm{P}_{2}, \mathrm{P}_{5}, \mathrm{P}_{6}$ are female students whilst $\mathrm{P}_{3}$ and $\mathrm{P}_{4}$ are male students.

\subsection{Instrument and Data Collection}

The data was collected through a semi-structured interview form developed by the two researchers and one expert considering national and international literature (NCTM, 2000; Ministry of National Education [MoNE], 2018). The interview form consists of seven open-ended questions to reveal the knowledge, experiences, behaviors and opinions of the students on the concept of measurement. Based on the expert opinions, some questions were revised for clarity and sub-items were added. The items were further reviewed and the items that were not found suitable for this study were removed. Moreover, the final form included some new sub-questions such as "Does every shape with a circumference have an area? Does every shape with an area have a volume?" Table 1 presents the questions in the interview form and the achievements associated with these questions (MoNE, 2018).

Regarding the third question in Table 1, the students were first asked to draw prisms with the same value for the comparison of the surface areas of two prisms with the same volume, but for those who failed to draw, they were given two rectangular prisms with the same volume. Because the achievement related to this question is that the student can solve the problems that require calculating the surface area of a rectangular prism. The students who took part in this study were informed of the objective of this study and the confidentiality of their personal information; then, a total of six students volunteer to participate in this study attended semi-structured interviews that lasted for about 35-45 minutes. The interviews were audio-recorded to prevent data loss. They were conducted with a "romantic" philosophical orientation, which allowed for the data to manifest themselves spontaneously in a friendly setting. Moreover, two researchers made observations during this process and took observation notes on the participants by paying attention to their gestures, mimics, tones and behaviors, which would be useful in understanding the case that are not fully identified during the interviews. 


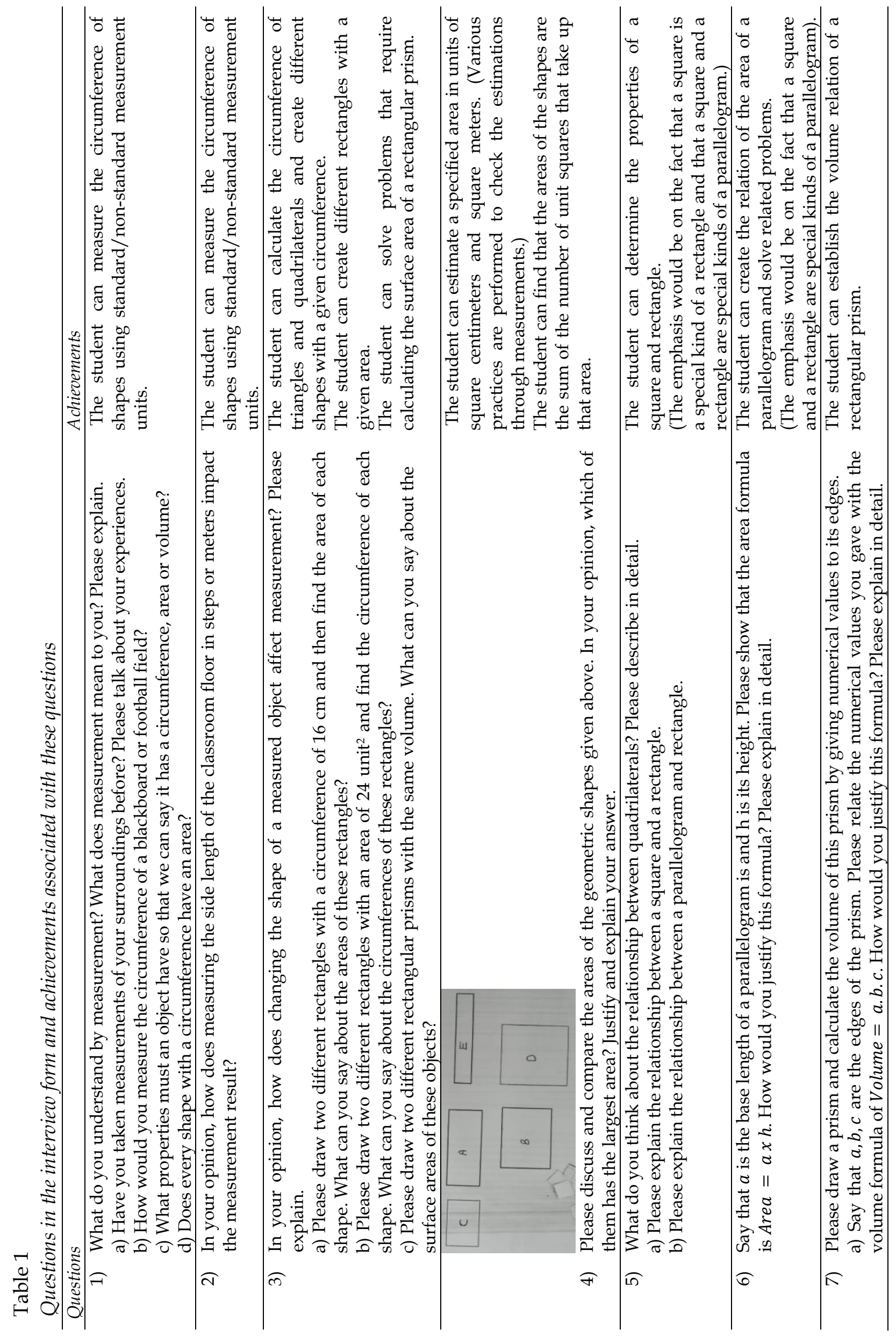




\subsection{Data Analysis}

The data analysis was performed through content and descriptive analysis methods. The categories and sub-categories were identified through descriptive analysis and the codes were developed via content analysis. In the descriptive analysis, the categories were developed based on the framework of two big ideas in the measurement area set by NCTM (2000). Accordingly, the data were analyzed under six categories as follows: "Measurable Attributes", "Equivalence", "Comparison", "Estimation/Approximate Value", "Describing, Classifying, Analyzing", "Using Standard/Non-Standard Measurement Tools", "Developing and Using Formulas for Measurement", "Using Appropriate Measurement Techniques." Further, the data sets identified similar to each other in the content analysis were grouped, gathered as themes or categories and then interpreted (Merriam, 2018). The data recorded during the interviews for the content analysis were transcribed by the researchers. Data sets were formed to include the observation and field notes as well as the interpretations of researchers related to each transcript. The data were imported into NVivo software and the data in each data set were coded to determine the total frequency for each code. The related codes were combined with the interpretations and field notes; categorizations were made based on the similarity of the data. Table 2 presents the framework of big ideas in NCTM (2000).

Table 2

The framework for analyzing the measurement approaches of students according to big ideas (NCTM, 2000)

\begin{tabular}{|c|c|c|c|}
\hline Big Ideas & $\begin{array}{l}\text { Category } \\
\text { Number }\end{array}$ & Category Name & Descriptions \\
\hline \multirow{5}{*}{ Big Idea 1) } & 1 & Measurable attributes & \multirow{5}{*}{$\begin{array}{l}\text { Understand the measurable } \\
\text { attributes of objects as well } \\
\text { as unit in measurement and } \\
\text { measurement processes }\end{array}$} \\
\hline & 2 & Equivalence & \\
\hline & 3 & Comparison & \\
\hline & 4 & Estimation/Approximate Value & \\
\hline & 5 & Describing, Classifying and Analyzing & \\
\hline \multirow{4}{*}{ Big Idea 2) } & 6 & Using Standard/Non-Standard & \multirow{4}{*}{$\begin{array}{l}\text { Apply formulas, } \\
\text { appropriate measurement } \\
\text { techniques } \\
\text { measurement tools to } \\
\text { determine measurements }\end{array}$} \\
\hline & & Measurement Tools & \\
\hline & 7 & $\begin{array}{l}\text { Developing and Using Formulas for } \\
\text { Measurement }\end{array}$ & \\
\hline & 8 & $\begin{array}{l}\text { Using Appropriate } \\
\text { Techniques }\end{array}$ & \\
\hline
\end{tabular}

As seen in Table 2, the category of "Measurable Attributes" consists of codes such as "measuring weight, measuring area, measuring length." For example, the code of "measuring circumference and area" is based on the answer of $\mathrm{P}_{2}$ to the question of "What do you understand by measurement? What does measurement mean to you? Please explain", which was as follows: "It is like finding the areas or circumferences of something, that is, an object." It was found during the research that some codes emphasized the same meaning, and different codes were combined to form a single code. For example, the codes of "measuring the width or length of something", "measuring width, length, height of objects" and "measuring size" that were identified in the same question were found to be similar to each other and these codes were grouped under the code of "measuring length." Likewise, the codes of "four-pointed shape", "parallelogram" and "right angles" identified in the category of "Describing, Classifying and Analyzing" geometrical shapes were grouped under the code of "comparing the properties (edge, angle, etc.) of shapes" through colleague confirmation. The agreement formula of Miles and Huberman (1994) was used for the reliability of the coding. The data were coded by two researchers independently and the agreement percentage of the codes was calculated as 0.91 . For the remaining difference of 9 percent, the researchers gathered to make a joint decision, and a complete agreement (100\%) was achieved. Besides, the resulting codes and categories were presented along with the supporting 
quotes from the interviews. For a possible re-assessment of the analyses conducted in this study, audio records and transcripts are available both electronically and in print. The researcher who led the research process had been lecturing the participants for a period of about three years before the study and thus was acquainted with them, which allowed for a sincere and reliable setting for the interviews. This enabled the participants to be sincere in their responses. Within the scope of validity and reliability, a pilot study was conducted with a student with the confirmation of the participant, as well as the coding agreement percentage and expert opinion. In this context, an application was made with a student other than the main study, and it was seen that the questions were understandable and suitable for the purpose.

\section{Findings and Interpretation}

The findings and interpretation section presents the codes from the interviews with the middle school $8^{\text {th }}$ grade students under certain categories as tables in the framework of two big ideas in $\operatorname{NCTM}(2000)$.

\subsection{Big Idea 1) Understand the measurable attributes of objects as well as unit in measurement and measurement processes}

\subsubsection{Findings on the category of measurable attributes}

Table 3 presents the findings on the category of measurable attributes. While the statements of some students were different in meaning but could be included in the same code, the statements of others were directly grouped in different codes. For that reason, the frequency number of the codes in tables refers to the number of statements, not the number of participants.

Table 3

Codes identified in the category of measurable attributes and the frequency values for these codes

\begin{tabular}{|c|c|c|c|c|}
\hline C & $S C$ & Codes & $f$ & Participants \\
\hline \multirow{14}{*}{ 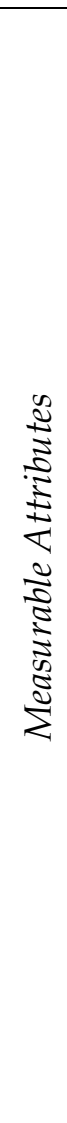 } & \multirow{8}{*}{ 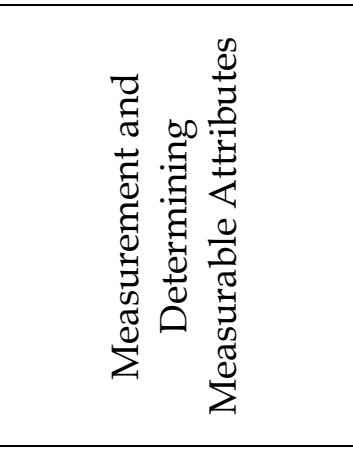 } & Measuring length & 20 & $\mathrm{P}_{2}, \mathrm{P}_{3}, \mathrm{P}_{4}, \mathrm{P}_{5}, \mathrm{P}_{6}$ \\
\hline & & Measuring area & 8 & $\mathrm{P}_{1}, \mathrm{P}_{2}, \mathrm{P}_{3}, \mathrm{P}_{4}, \mathrm{P}_{5}, \mathrm{P}_{6}$ \\
\hline & & Measuring weight & 5 & $\mathrm{P}_{2}, \mathrm{P}_{5}, \mathrm{P}_{6}$ \\
\hline & & Measuring certain shapes/objects & 4 & $\mathrm{P}_{2,}, \mathrm{P}_{3}, \mathrm{P}_{4}$ \\
\hline & & Measuring circumference & 4 & $\mathrm{P}_{1}, \mathrm{P}_{2}, \mathrm{P}_{4}, \mathrm{P}_{6}$ \\
\hline & & Measuring volume & 4 & $\mathrm{P}_{2,} \mathrm{P}_{5}$ \\
\hline & & Not requiring measurement & 2 & $\mathrm{P}_{1}, \mathrm{P}_{4}$ \\
\hline & & $\begin{array}{lll}\begin{array}{l}\text { Requiring } \\
\text { comparison }\end{array} & \text { measurement for } \\
\end{array}$ & 2 & $\mathrm{P}_{3}, \mathrm{P}_{5}$ \\
\hline & \multirow{2}{*}{ 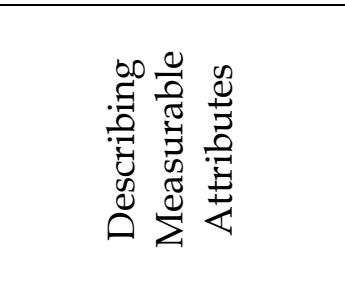 } & $\begin{array}{l}\text { Circumference is the sum of the } \\
\text { lengths of the four sides }\end{array}$ & 2 & $\mathrm{P}_{1}$ \\
\hline & & $\begin{array}{l}\text { Volume is the space/amount/weight } \\
\text { inside the object or volume refers to } \\
\text { filling the object with units or the } \\
\text { space occupied in the world }\end{array}$ & 5 & $P_{1}, P_{2}, P_{4}, P_{5}, P_{6}$ \\
\hline & \multirow{4}{*}{ 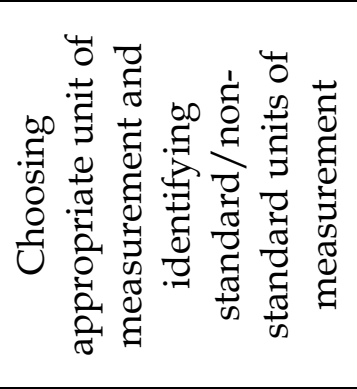 } & $\begin{array}{l}\text { Using non-standard units of } \\
\text { measurement }\end{array}$ & 14 & $\mathrm{P}_{1}, \mathrm{P}_{2}, \mathrm{P}_{3}, \mathrm{P}_{4}, \mathrm{P}_{5}$ \\
\hline & & $\begin{array}{l}\begin{array}{l}\text { Useful unit of measurement } \\
\text { (difficult/easy to use) }\end{array} \\
\end{array}$ & 7 & $P_{1}, P_{3}, P_{4}$ \\
\hline & & $\begin{array}{l}\text { Need for appropriate units of } \\
\text { measurement }\end{array}$ & 7 & $P_{1}, P_{3}, P_{5}, P_{6}$ \\
\hline & & $\begin{array}{l}\text { Using standard units of measurement } \\
(\mathrm{km}, \mathrm{m}, \mathrm{cm})\end{array}$ & 4 & $\mathrm{P}_{3}$ \\
\hline
\end{tabular}

C: Category, SC: Sub-category 
As seen in Table 3, the most repetitive codes in the sub-category of measurement and measurable attributes are "measuring length" $(f=20)$ and "measuring area" $(f=8)$. This means that the students measured the properties of the shapes such as length and area as well as width and height most. Also, the students failed to provide any description for the question of "What do you understand by measurement? What does measurement mean to you?" and mostly defined measurement as measuring length, width and height and calculating area, circumference and volume. For that reason, it seems that the students failed to express measurement conceptually. The reason for this may be that the students do not feel the need to make measurements in everyday life. Indeed, two participants $\left(\mathrm{P}_{1}\right.$ and $\left.\mathrm{P}_{4}\right)$ stated that they do not feel to make measurements in their daily life in the interviews. Thus, it is possible to argue that the conceptual understanding of the students on measurement is based on the idea that measurement is mostly about calculating length, area and volume. The quotes from the statements of some participants on this are as follows:

"It is like finding the area of an object, calculating its circumference... we always use that word with circumference."(P6)

"Measurement is measuring the width or length of something" (P4)

"It is the space occupied by an object, its length" (P5)

In the sub-category of describing measurable attributes, there are different perceptions on the concept of volume. The perceptions of some students on volume are limited to the volume occupied whilst that of others is limited to internal volume. When compared, the number of the students with a perception of internal volume is higher. It follows from that the understanding of the students on volume is restricted. This is also supported by the fact that although the students defined area, volume and circumference as measurable attributes, they developed misconceptions such as "area is the place in the world; area is volume." The quotes from the statements of the participants illustrate this situation:

R: What do you understand by measurement? Does everything have an area?

$\mathrm{P}_{4}$ : The volume that an object occupies in the world.

$\mathrm{R}$ : Do you think the volume and area are the same?

$\mathrm{P}_{4}$ : Area is where it occupies in the world.

$\mathrm{R}$ : If area is where it occupies in the world, what is volume?

$\mathrm{P}_{4}$ : Volume is where it occupies in the world too.

R: Well, does this paper have a volume?

$\mathrm{P}_{4}$ : Volume is something else. If area is where it occupies in the world, it is something calculated with length and width.

The most repetitive code in the sub-category of choosing appropriate unit of measurement and identifying standard/non-standard units of measurement is the code of "using non-standard unit of measurement" ( $\mathrm{f}=14)$. In the interviews, the students reported that they used pace $(\mathrm{f}=5)$ and span $(\mathrm{f}=4)$ most among the non-standard units of measurement whilst they preferred foot, A4 size paper, book and stroke least (all with only one frequency). This means that the perceptions of the students on their use of non-standard units of measurement for measurement are mostly limited to measuring length. Because none of the students came up with an idea such as using unit squares in measuring area and using unit cubes in measuring volume. Although the use of non-standard units in measurement makes it easier for the students to focus on the measured quality, it seems that the use of measurement units limited to length leads them to develop incomplete understanding of area and volume. Another important finding is that the students are unable to clearly define the concept of unit in measurement and to construct the relationship between unit and dimension. In the measurements where the students used unit squares, they expressed the unit of measurement for area as "unit" rather than "unit square." The same applies to the measurement of volume. One of the most repetitive codes in this category is the code of "unit of measurement needs to be useful (difficult/easy) $(\mathrm{f}=7$ ). In the interviews, the students reported that while choosing the appropriate unit of measurement, one needs to take into consideration the usefulness of the unit of measurement for the given operation and for the interpretation of the measurement 
results. From this standpoint, the students need appropriate units of measurement. In relation to this, the direct quotes from the statements of some students are as follows:

"For example, it takes too long to measure a road in centimeters or something. So, it would be ridiculous to measure the distance between Istanbul and Ankara in centimeters. It would also be difficult to read it as a number, so measuring in kilometers would be easier and easier to read." (P2)

"For example, if we measure it with a ruler, it would be very difficult and would take a lot of time. For example, we may forget the numbers while adding them. But we can easily measure it with a tape measure." (P1)

\subsubsection{Findings on the category of equivalence}

Table 4 presents the codes identified in the category of Equivalence, which means involves expressing measurement results using different units in equivalent ways, and the frequency values for these codes.

Table 4

Codes identified in the category of equivalence and the frequency values for these codes

\begin{tabular}{|c|c|c|c|}
\hline Category & Codes & $f$ & Participants \\
\hline \multirow{2}{*}{ Equivalence } & $\begin{array}{l}\text { Using different units of measurement changes the } \\
\text { measurement result. }\end{array}$ & 5 & $P_{1}, \quad P_{2}, P_{3}, P_{5}$ \\
\hline & $\begin{array}{l}\text { Using different units of measurement does not change } \\
\text { the measurement result. }\end{array}$ & 2 & $\mathrm{P}_{4}, \mathrm{P}_{6}$ \\
\hline
\end{tabular}

As obvious in Table 4, most of the students believed that "using different units of measurement changes the measurement result" $(\mathrm{f}=5)$; on the other hand, some students argued that using different units of measurement does not change the measurement results. This is perhaps best illustrated by the following dialogue between the researcher and the students on the question of "In your opinion, how does measuring the side length of the classroom floor in steps or meters impact the measurement result?":

R: Well, you measured it with your own sole. I measured it with my own. Consequently, what can you say about the measurement result?

$\mathrm{P}_{2}$ : Actually, it does not change much. Because we will multiply it with our own shoe soles; for example, if it is 10 centimeters and 20 paces, we will multiply 10 with 20 . So it is 200 centimeters and will still be so even if you measure it. Only the size of shoes increase. The distance, that is, the paces you take, become shorter.

R: So, how does this change the measurement result? In other words, you measure in paces and then in meters, what would be the result?

$P_{5}$ : It may change. For example, my pace may be different from that of other.

R: Well, what would be the measurement results? So, let's say you measure it and find 10 paces, what would I find if I measure?

$P_{5}$ : Twenty, no it would be less.

R: Let's say it would be seven. So, would be this an inaccurate measurement?

P5: How should I put it? As it changes depending on shoe size, it would not be inaccurate but it changes. But, it does not change if I measure it in meters. My measurement and your measurement would be the same.

\subsubsection{Findings on the Category of Comparison}

Table 5 presents the codes identified in the category of comparison of the relative values of measurement results such as circumference, area and volume as measurable attributes as well as the frequency values for these codes. 
Table 5

Codes identified in the category of comparison and the frequency values for these codes

\begin{tabular}{|c|c|c|c|c|}
\hline Category & Sub-categories & Codes & $f$ & Participants \\
\hline \multirow{17}{*}{ Comparison } & \multirow{10}{*}{$\begin{array}{l}\text { Comparison of } \\
\text { Circumference- } \\
\text { Area }\end{array}$} & $\begin{array}{l}\text { Circumference and area are directly } \\
\text { proportional. }\end{array}$ & 6 & $\mathrm{P}_{2}, \mathrm{P}_{4}, \mathrm{P}_{5}, \mathrm{P}_{6}$ \\
\hline & & $\begin{array}{l}\text { It is possible to create different rectangles } \\
\text { with the same area. }\end{array}$ & 6 & $\mathrm{P}_{1}, \mathrm{P}_{2}, \mathrm{P}_{3}, \mathrm{P}_{4}, \mathrm{P}_{6}$ \\
\hline & & $\begin{array}{l}\text { Although they have the same area, their } \\
\text { circumferences may be different }\end{array}$ & 5 & $\mathrm{P}_{1}, \mathrm{P}_{3}, \mathrm{P}_{4}, \mathrm{P}_{6}$ \\
\hline & & $\begin{array}{l}\text { It is possible to create different rectangles } \\
\text { with the same circumference. }\end{array}$ & 4 & $\mathrm{P}_{2}, \mathrm{P}_{3}, \mathrm{P}_{4}, \mathrm{P}_{6}$ \\
\hline & & $\begin{array}{l}\text { A shape with a circumference also has an } \\
\text { area. }\end{array}$ & 3 & $\mathrm{P}_{5}, \mathrm{P}_{6}$ \\
\hline & & If there is area, there must be circumference. & 3 & $\mathrm{P}_{4}, \mathrm{P}_{5}, \mathrm{P}_{6}$ \\
\hline & & $\begin{array}{l}\text { A shape with a circumference also may not } \\
\text { have an area. }\end{array}$ & 2 & $\mathrm{P}_{1}, \mathrm{P}_{4}$ \\
\hline & & $\begin{array}{l}\text { If the difference in the side lengths of the } \\
\text { shapes increases, area increases/decreases. }\end{array}$ & 2 & $\mathrm{P}_{2}$ \\
\hline & & $\begin{array}{l}\text { It is not possible to create different rectangles } \\
\text { with the same area. }\end{array}$ & 1 & $P_{5}$ \\
\hline & & $\begin{array}{l}\text { Circumference and area are inversely } \\
\text { proportional. }\end{array}$ & 1 & \\
\hline & \multirow{4}{*}{$\begin{array}{l}\text { Comparison of } \\
\text { Area-Volume }\end{array}$} & $\begin{array}{l}\text { If they have the same volume, their surface } \\
\text { areas are the same. }\end{array}$ & 3 & $\mathrm{P}_{4}, \mathrm{P}_{5}$ \\
\hline & & $\begin{array}{l}\text { If they have the same volume, their surface } \\
\text { areas are different. }\end{array}$ & 3 & $\mathrm{P}_{3}$ \\
\hline & & $\begin{array}{l}\text { Surface area and volume are directly } \\
\text { proportional. }\end{array}$ & 2 & $\mathrm{P}_{2,} \mathrm{P}_{6}$ \\
\hline & & $\begin{array}{l}\text { An object with a surface area may not have } \\
\text { any volume. }\end{array}$ & 1 & $\mathrm{P}_{6}$ \\
\hline & \multirow{3}{*}{$\begin{array}{l}\text { Relative } \\
\text { comparisons }\end{array}$} & $\begin{array}{l}\text { Making comparisons based on the length and } \\
\text { width relationship }\end{array}$ & 3 & $\mathrm{P}_{2,} \mathrm{P}_{4,}, \mathrm{P}_{6}$ \\
\hline & & Making random comparisons & 3 & $\mathrm{P}_{1}, \mathrm{P}_{5}, \mathrm{P}_{6}$ \\
\hline & & Need for numbers to make comparisons & 3 & $\mathrm{P}_{1}, \mathrm{P}_{2,} \mathrm{P}_{3}$ \\
\hline
\end{tabular}

As observed in Table 5, the most common codes for the question of "In your opinion, how does changing the shape of a measured object affect measurement?" in the sub-category of comparison of circumference and area are "circumference and area are directly proportional" $(\mathrm{f}=6)$ and "it is possible to create different rectangles with the same area" $(\mathrm{f}=6)$. From this standpoint, the students mostly believed that if circumference increases, area increases and if circumference decreases, area decreases too. Only one student $\left(\mathrm{P}_{3}\right)$ believed that circumference and area are inversely proportional. However, when circumference increases, area increases/decreases or does not change. For example, when the circumference of a concave polygon increases, its area may decrease. On the other hand, when the area of a square with a side length of 4 units is compared with the area of a rectangle with a width of 2 units and a length of 8 units, the circumference increases, but their areas are equal. That is, it is notable that the students did not embrace a flexible conceptual understanding that the circumference or area of objects changes, the other one would increase/decrease or would not change. Therefore, the students failed to adequately construct the concept of invariance and developed a limited understanding in comparison of circumference with area. One of the remarkable findings on the comparison of circumference with area is related to the question of "Is it possible to draw different rectangles with the same area?"; the students successfully 
drew two different rectangles with an area of 24 unit $^{2}$. It is remarkable that the students preferred drawing rectangles with similar side lengths (short edge of 4 units and long edge of 6 units) or with very different side lengths (short edge of 1 unit and long edge of 24 units).

Also, the most common codes for the question of "What can you say about the surface areas of prisms with the same volume?" in the sub-category of comparison of area and volume are "if they have the same volume, their surface areas are the same" ( $f=3)$ and "if they have the same volume, their surface areas are different" $(\mathrm{f}=3)$. This shows that the students tended to accept either of the two situations: the surface areas of prisms with the same volume are the same or the surface areas of prisms with the same volume are different. That is, the students overlooked that both situations can be valid. This is also supported by the fact that the students believed that volume and surface area are directly proportional. In other words, according to the students, if volume increases, surface area increases too or if volume decreases, surface area decreases too. Yet, if volume increases, surface area may increase, decrease or does not change at all. For example, comparing the surface area of a rectangular prism with edges of 1 unit, 2 units and 11 units and that of another rectangular prism with edges of 2 units, 3 units and 4 units, one might say that the latter prism has a bigger volume but a smaller surface area. Similarly, comparing the surface area of a rectangular prism with edges of 1 unit, 2 units and 10 units and that of another rectangular prism with edges of 2 units, 4 units and 4 units, one might say that the latter prism has a bigger volume but their surface areas are equal. This finding is perhaps best illustrated by the following dialogue between the researcher and $\mathrm{P}_{4}$ on the comparison of the surface areas of the rectangular prisms with the same volume (See. Figure 1).

Figure 1

Rectangular prisms with the same volume

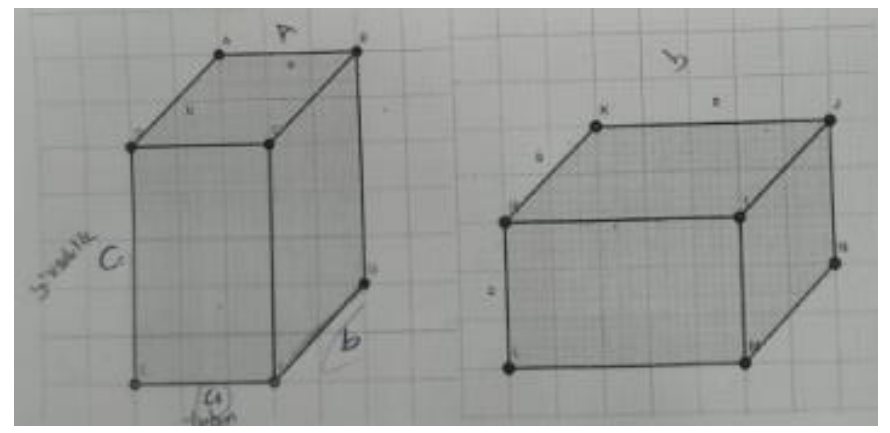

R: Well, let's say you have two different prisms with the same volume. What can you say about the surface areas of these prisms?

$\mathrm{P}_{4}$ : The surface areas are the same.

R: Why so?

$\mathrm{P}_{4}$ : The upper surface of B is large and the side surface of A is large, but other areas are pretty much the same.

R: How did you conclude that other areas are pretty much the same? What made you think so?

$\mathrm{P}_{4}$ : Well, I concluded based on partly what I see and partly what I predict.

One of the most significant findings on the comparison of surface area and volume is that the students developed the understanding that "surface area is the area in contact with the ground." This study also found that some students $\left(\mathrm{P}_{2}, \mathrm{P}_{6}\right)$ even accepted the base of prisms as surface area and commented on the surface areas of prisms by considering only one of the edge lengths at the base (See. Figure 2). This indicates that the students failed to construct the surface area due to their misinterpretation of edge and base. Thus, it can be argued that the students had a hard time with reasoning on measurement of surface area and volume because of the misconception of the students on certain concepts. The quote from the statements of $\mathrm{P}_{4}$ would perhaps best represent this situation: 
R: Let's say you have two different rectangular prisms named A and B. Their volume is the same; what can you say about their surface areas?

$\mathrm{P}_{4}$ : Their surface areas are not the same.

R: Why?

$\mathrm{P}_{4}$ : The surface area of the prism named A is smaller, because it occupies less area (showing the length of 3 units).

$\mathrm{R}$ : Where is the surface area?

$\mathrm{P}_{4}$ : It is the space covered by the area that the prism is in contact with.

$\mathrm{R}$ : Then, what are you saying?

$\mathrm{P}_{4}$ : The surface area of $\mathrm{A}$ is smaller and that of $\mathrm{B}$ is larger (showing the length of 5 units). But if we place B like A, their volumes will be the same as the space occupied by them will be the same.

$\mathrm{P}_{4}$ : The surface area is the area it covers, and the volume is the area it takes up in the world. Their areas are equal so I think their volumes are also equal.

Figure 2

The answer of P4 on the surface areas of the prisms

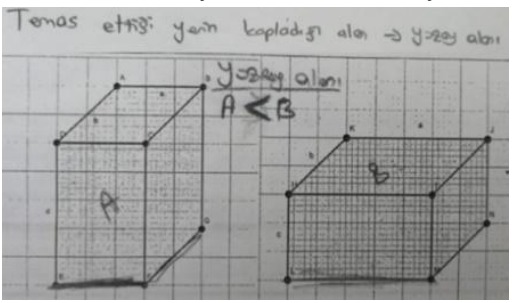

In the sub-category of relative comparisons, the students were given five different geometric shapes with the same or different areas (See. Figure 3) and asked the question of "What can you say about the areas of geometric shapes? Please compare them and show which of them has the largest area. Justify and explain your answer." Making comparisons based on "the length and width relationship" $(\mathrm{f}=3)$, the students did not benefit from any comparison strategy and "made random comparisons" $(\mathrm{f}=3)$ and "needed numbers to make comparisons" $(\mathrm{f}=3)$. The students mostly focused on the length and width relationship of the shapes in their comparisons. Some students focused on the width particularly while comparing the geometric shape of $\mathrm{E}$ with a thin width and long length and the geometric shape of $C$ with a thick width and short length. Further, the students did not mention any area measurement strategy for the comparison of the shapes with similar or the same areas, such as using unit squares or folding paper; they rather reported that it is not possible to make any comparison. This clearly shows that the students have a limited understanding of comparison. An example of this is the following dialogue between the researcher and the students:

Figure 3

Geometric shapes with the same and different areas

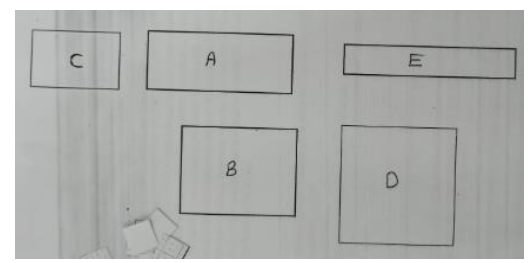

$\mathrm{P}_{4}$ : Teacher, it seems $\mathrm{D}$ is larger; the width of $\mathrm{E}$ is thinner than that of $\mathrm{C}$ but its length is longer than that of C. I could not make up my mind.

$\mathrm{R}$ : What are you thinking?

$\mathrm{P}_{4}$ : It looked like E was larger when I first looked at it, but after I thought about it for a while, it was like it's not. 


\subsubsection{Findings on the Category of Estimation/Approximate Value}

Table 6 presents the codes identified in the measurement of approximate values using benchmarks known as units based on the measurement results such as length, area and volume as well as the frequency values for these codes.

Table 6

Codes identified in the category of estimation/approximate value and the frequency values for these codes

\begin{tabular}{lllll}
\hline \multirow{2}{*}{$\begin{array}{l}\text { Estimation/Approximate } \\
\text { Value }\end{array}$} & $\begin{array}{l}\text { Codes } \\
\text { Dimensional estimation (Using benchmarks, } 11\end{array} \mathrm{P}_{2}, \mathrm{P}_{4}, \mathrm{P}_{5}, \mathrm{P}_{6}$ \\
& $\begin{array}{l}\text { repeating units, using prior knowledge, rough } \\
\text { estimation, visualization) }\end{array}$ & & \\
\hline
\end{tabular}

As Table 6 shows, regarding the estimation of measurement results, the opinions expressed by the students were mostly about dimensional estimation, rather than measurement estimation, or operational/computational estimation. As for the measurement strategies applied by the students, it is notable that some of them made estimations using non-standard units of measurement, that is, the strategy of repeating units $(\mathrm{f}=6)$; on the other hand, others benefited from a benchmark such as a book or goal to make estimates. This situation is perhaps best illustrated by the following dialogue between the researcher and $\mathrm{P}_{2}$ :

$\mathrm{R}$ : There is a soccer field in front of the school building, right? How would you measure the circumference of that soccer field?

$\mathrm{P}_{2}$ : We can measure it using our foot. I do not think we can measure it with our steps. We may take every step differently and thus we may not reach a close result. But if we know our sole length, we can find the result in the unit of sole length.

Well, you measured it with your own sole. I measured it with my own. Consequently, what can you say about the measurement result?

$\mathrm{P}_{2}$ : Actually, it does not change much. Because we will multiply it with our own shoe soles; for example, if it is 10 centimeters and 20 paces, we will multiply 10 with 20 . So, it is 200 centimeters and will still be so even if you measure it. Only the size of shoes increases. The distance, that is, the paces you take, become shorter.

This dialogue points out that in estimating the circumference of a soccer field, the student makes his/her estimation through unit repetition by taking into consideration the length of his/her shoe sole. Indeed, this estimation strategy typically benefits from non-standard units of measurement such as span, stroke and pace (Budak \& Okur, 2012). For instance, considering the length of a shoe sole as about $10 \mathrm{~cm}, \mathrm{P}_{2}$ stated that taking 20 steps would yield a result of $200 \mathrm{~cm}$. It is remarkable that this and similar situations the students developed certain understanding for calculating approximate values based on estimation, using units as benchmarks in measurement. Only one of the students who stated an opinion on a different strategy for dimensional estimation $\left(\mathrm{P}_{6}\right)$ drew on the strategy of using prior knowledge $(\mathrm{f}=1)$ benefiting from standard units of measurement to make estimates. Indeed, emphasis should be placed on the use of standard units of measurement in understanding the concept of unit. As estimates based on standard units of measurement as a benchmark (e.g., the height of the door is less than two meters) are very effective in developing the concept of large/small for units (NCTM, 2000). It is also interesting that four students, who expressed different opinions on dimensional estimation, utilized the strategy of random comparisons. In comparisons of area and volume, these students did not use any unit as a benchmark, and they simply made estimates mostly by looking at the given shapes. A quote from $\mathrm{P}_{4}$ regarding this is as follows:

R: Well, let's say you have two different prisms with the same volume. What can you say about the surface areas of these prisms?

$\mathrm{P}_{4}$ : The surface areas are the same.

R: Why so? 
$\mathrm{P}_{4}$ : The upper surface of B is large, and the side surface of A is large, but other areas are pretty much the same.

R: How did you conclude that other areas are pretty much the same? What made you think so?

$\mathrm{P}_{4}$ : Well, I concluded based on partly what I see and partly what I predict.

\subsubsection{Findings on the category of describing, classifying and analyzing}

The responses of the students to the question of "What do you think about the relationship between a square and a rectangle, and a rectangle and a parallelogram?", which was intended to reveal the relationships between different geometrical shapes, are discussed in the category of describing, classifying and analyzing. Table 7 presents the codes identified in this category as well as the frequency values for these codes.

Table 7

Codes identified in the category of describing, classifying and analyzing and the frequency values for these codes

\begin{tabular}{llcl}
\hline Category & Codes & $f$ & Participants \\
\hline \multirow{4}{*}{$\begin{array}{c}\text { Describing, } \\
\text { Classifying } \\
\text { and Analyzing }\end{array}$} & $\begin{array}{l}\text { Comparing the properties of shapes (edge, angle, etc.) } \\
\text { for classification }\end{array}$ & 12 & $\mathrm{P}_{1}, \mathrm{P}_{2}, \mathrm{P}_{3}, \mathrm{P}_{4}, \mathrm{P}_{5}, \mathrm{P}_{6}$ \\
\cline { 2 - 4 } & Considering the shapes of objects for description & 5 & $\mathrm{P}_{1}, \mathrm{P}_{2}, \mathrm{P}_{3}, \mathrm{P}_{6}$ \\
\cline { 2 - 4 } & Considering the shapes of objects for classification & 3 & $\mathrm{P}_{1}, \mathrm{P}_{5}, \mathrm{P}_{6}$ \\
\cline { 2 - 4 } & $\begin{array}{l}\text { Square and rectangular are not related } \\
\text { Square and rectangle are related; but a square is not a } \\
\text { rectangular }\end{array}$ & 3 & $\mathrm{P}_{6}, \mathrm{P}_{5}$ \\
\cline { 2 - 4 } & A parallelogram is a rectangular & 2 & $\mathrm{P}_{1}, \mathrm{P}_{2}$ \\
\cline { 2 - 4 } & A rectangular is a square & 1 & $\mathrm{P}_{6}$ \\
\hline
\end{tabular}

As Table 7 indicates, the students mostly "compared the properties of shapes (edge, angle, etc.) for classification" ( $f=12)$ for the classification of the geometric shapes. In the interviews, the students highlighted on the critical properties of shapes such as "having four corners", "having parallel sides" and "having right angles" but failed to reason to classify them. The reason may be that although some students focused on these critical properties in their statements, they believed that "square and rectangular are not related" $(\mathrm{f}=3)$ or "Square and rectangle are related; but a square is not a rectangular" $(\mathrm{f}=3)$. For that reason, the students took into consideration the critical properties of the geometric shapes for classification, but they failed to construct the relationship between the geometric shapes. Some quotes from the dialogue between the researcher and the students on this finding are as follows:

$\mathrm{P}_{4}$ : All four sides of a square are equal, but the long and short sides of a rectangle are different.

R: Are there any other properties of these shapes? Properties that make them similar or different?

$\mathrm{P}_{4}$ : A rectangle has different sides.

R: Well, a shape must have different sides so that I can call it a rectangle?

$\mathrm{P}_{4}$ : Its long and short sides must be different.

$\mathrm{R}$ : Would not be a rectangle if they were equal?

$\mathrm{P}_{4}$ : If they were equal, it would be a square.

R: Okay, do you want to say something else about this?

P4: No...

R: Could a rectangle have equal sides?

$\mathrm{P}_{2}$ : No. Otherwise, the resulting shape has a special name; it is called square.

R: A special name called square. A special name for what?

$\mathrm{P}_{2}$ : A rectangle with equal sides.

R: Then, what can you conclude about square and rectangle? Well, can you provide any explanation?

$\mathrm{P}_{2}$ : So, if all sides are equal, it is a square; if not, it is a rectangle. 
The above dialogue between the researcher and $\mathrm{P}_{2}$ demonstrates that $\mathrm{P}_{2}$ stated that a rectangle with equal sides is specially called a square. Yet, the student failed to conclude that a square is a special kind of a rectangle as $\mathrm{s} /$ he could not establish the hierarchical relationship between a square and a rectangle. In this regard, it is possible to argue that the students did not take into account the hierarchical structure between geometric shapes and evaluated each geometric shape within its own limits, overlooking its relationship with other geometric shapes. Because none of the students stated that a square is also a rectangle or that a rectangle is also a parallelogram. Rather, they mostly believed that "a parallelogram is a rectangle." Another finding on the relationship between geometric shapes, the students failed to define a rectangle as a parallelogram although they were able to create the area relation of a parallelogram "based on the area relation of a rectangle", they failed to describe a rectangle as a parallelogram. This is further discussed in the category of developing and using formulas for measurement.

\subsection{Big Idea 2) Apply formulas, appropriate measurement techniques and measurement tools to determine measurements}

\subsection{Findings on the category of using standard/non-standard measurement tools}

Table 8 shows the codes identified in the category of selecting and using standard/non-standard measurement tools as well as the frequency values for these codes.

Table 8

Codes Identified in the category of using standard/non-standard measurement tools and the frequency values for these codes

\begin{tabular}{|c|c|c|c|}
\hline Category & Codes & $f$ & Participants \\
\hline \multirow{6}{*}{$\begin{array}{l}\text { Using standard/non- } \\
\text { standard } \\
\text { measurement tools } \\
\text { for measurement }\end{array}$} & Meter & 16 & $\mathrm{P}_{1}, \mathrm{P}_{2}, \mathrm{P}_{3}, \mathrm{P}_{4}, \mathrm{P}_{5}, \mathrm{P}_{6}$ \\
\hline & Rope & 2 & $\mathrm{P}_{5}$ \\
\hline & Stick & 2 & $\mathrm{P}_{1}, \mathrm{P}_{4}$ \\
\hline & Ruler & 2 & $\mathrm{P}_{1}, \mathrm{P}_{2}$ \\
\hline & A4 size paper/Book & 2 & $\mathrm{P}_{2}, \mathrm{P}_{4}$ \\
\hline & Dynamometer & 1 & $\mathrm{P}_{6}$ \\
\hline
\end{tabular}

Table 8 demonstrates that the students mentioned "meter" $(\mathrm{f}=16)$ most among the measurement tools. That is, the understanding of the students regarding the measurement tools is mostly based on the measurement tools intended to measure length. Because, during the interviews, none of the students mentioned the use of measurement tools such as graduated bowl, unit cubes for measuring volume and materials such as squared paper/book/A4 size paper for measuring area or glass. The students considerably focused on measuring length. Thus, it is possible to argue that the understanding of the students regarding the use of measurement tools is limited to "meter."

\subsubsection{Findings on the category of developing and using formulas for measurement}

Table 9 presents the codes identified in the category of developing and using formulas for circumference, area and volume measurement and the frequency values for these codes.

Table 9 points out that the understanding of "creating formulas based on memorization" ( $f=7$ ) was dominant among the students in the category of developing and using formulas for measurement. In the interviews, the students mostly used the widely known formulas based on memorization in calculating circumference, area and volume. For example, to measure the circumference of a rectangle, some students multiplied the lengths of two adjacent sides, through which one finds the area of a rectangle, but they expressed this as its circumference. Similarly, although the students were familiar with the volume formula for prisms, they had a hard time in 
Table 9

Codes identified in the category of developing and using formulas for measurement and the frequency values for these codes

\begin{tabular}{|c|c|c|}
\hline Category & Codes & Participants \\
\hline \multirow{6}{*}{$\begin{array}{c}\text { Developing and } \\
\text { using formulas } \\
\text { for } \\
\text { measurement }\end{array}$} & Creating formulas based on memorization & $\mathrm{P}_{1}, \mathrm{P}_{2}, \mathrm{P}_{3}, \mathrm{P}_{4}$ \\
\hline & $\begin{array}{l}\text { Failing to construct the relationship between formula } \\
\text { and unit-dimension }\end{array}$ & $P_{1}, P_{2}, P_{3}, P_{5}$ \\
\hline & $\begin{array}{l}\text { Establishing the link between the area formulas of } \\
\text { rectangles and parallelograms }\end{array}$ & $5 \quad \mathrm{P}_{1}, \mathrm{P}_{2}, \mathrm{P}_{3}, \mathrm{P}_{4}, \mathrm{P}_{5}$ \\
\hline & $\begin{array}{l}\text { Establishing the link between formula and the real } \\
\text { object }\end{array}$ & $2 \quad \mathrm{P}_{2}, \mathrm{P}_{6}$ \\
\hline & $\begin{array}{l}\text { Embracing an algebraic/numerical approach in } \\
\text { using formulas }\end{array}$ & $2 \mathrm{P}_{2}, \mathrm{P}_{6}$ \\
\hline & $\begin{array}{l}\text { Considering edge length/height in the formula as } \\
\text { the base of the geometric shape }\end{array}$ & \\
\hline
\end{tabular}

establishing the link between formula and the real object. An example of this is the following dialogue between the researcher and $\mathrm{P}_{1}$ :

R: Well, let me tell you, there is a rectangular prism over there, right? Now, let me say that volume= axbxc. What does this formula mean to you?

$P_{1}$ : When you multiply three corners, you come up with its volume

R: Three corners?

$\mathrm{P}_{1}$ : I mean three edges.

R: Well, what do you think about the relationship between this volume formula and prism? Could you please explain?

$P_{1}$ : I'm writing a,b,c

R: So, how are this formula and prism related? For example, in your opinion, what is this a?

$\mathrm{P}_{1}$ : The length of an edge.

As seen in the above dialogue, $\mathrm{P}_{1}$ first stated that the letters in the volume formula are the corners of a prism and then changed his/her statement by saying that these letters are the edges of $a$ prism upon the intervention of the researcher. In the interviews, though $\mathrm{P}_{1}$ indicated the base edges of the prism with $\mathrm{b}$ and $\mathrm{c}$ and its height with $\mathrm{a}, \mathrm{s} /$ he failed to express that a refers to the height of the prism or that $b \times c$ is the base area. Therefore, it is possible to claim that $P_{1}$ has memorized the volume formula and failed to construct the concept of edge. Same thing applies to $\mathrm{P}_{4}$. Indeed, $\mathrm{P}_{4}$ acknowledged that $\mathrm{a}, \mathrm{b}$ and $\mathrm{c}$, which were given in the volume formula, are related to the edges of the prism, but described them as "three central and significant lengths." Upon the question of "What do you mean by central?" by the researcher, the student came up with non-conceptual explanations and stated that "the whole object, all of that." This means that the students had a hard time in identifying the properties of the prism represented by the variables given in the volume formula for prism. The dialogue between the researcher and $\mathrm{P}_{4}$ would be a great example of this finding:

R: Could you associate the letters in the formula with the shape? For example, associate a letter with the height.

$\mathrm{P}_{4}$ : In my opinion, $\mathrm{c}$ refers to the height.

R: So, with what are you multiplying the height?

$\mathrm{P}_{4}$ : Base... This edge...

R: What do you mean by the base?

$\mathrm{P}_{4}$ : That is, the base of that object. The three central corners are multiplied.

R: Corners?

$\mathrm{P}_{4}$ : I mean length. The three central and significant lengths are multiplied to calculate the volume.

$\mathrm{R}$ : What do you mean by central?

$\mathrm{P}_{4}$ : The whole object, all of that. 
It is notable that some students overlooked the height in the volume formula for prism, considered edge as base, were confused with the concepts of base, corner and length, and mistook height for base $(\mathrm{f}=2)$ and believed that the surface area of the prism is the area where it is in contact with the ground. This indicates that the students could not fully construct concepts such as edge, corner, height and base. This is the primary reason why the students failed to construct the volume formula. This situation would be best illustrated by the following dialogue between the researcher and $\mathrm{P}_{6}$ :

R: Could you calculate the volume of the prism you've drawn?

$\mathrm{P}_{6}$ : In my opinion, it is not possible to calculate the volume of the prism if no information on its lengths is given.

R: How would you calculate if information was given?

$\mathrm{P}_{6}$ : Then, I would count it and write it down.

$\mathrm{R}$ : Well, what do $\mathrm{a}, \mathrm{b}, \mathrm{c}$ refer to in the formula of volume $=\mathrm{a} \times \mathrm{b} \times \mathrm{c}$ ?

$\mathrm{P}_{6}$ : They refer to how to calculate the volume. Here, a refers to one of its bases and $b$ refers to the other base, and $\mathrm{c}$ is its height. Because as the volume is calculated by multiplying the area of the base by the height, I call $a$ and $b$ the base and $c$ the height. Then, I multiply $a$ and $b$ by $c$.

R: So, what does the volume formula mean to us?

$\mathrm{P}_{6}$ : The volume formula is base times height.

This dialogue clearly shows that though $\mathrm{P}_{6}$ knew that the volume formula is base times height, $\mathrm{s} /$ he called $\mathrm{a}$ and $\mathrm{b}$ in the formula of $\mathrm{V}=\mathrm{a} \times \mathrm{b} \times \mathrm{c}$ as the base. Thus, it is possible to argue that $\mathrm{P}_{6}$ did not know the concept of edge and mistook edge for base. Also, $\mathrm{P}_{6}$ stated that $\mathrm{s} /$ he could not calculate the volume of the prism without any numerical value given. This indicates that $\mathrm{P}_{6}$ needs numbers to use formulas. As for the area relation of a parallelogram, the question of "Could you show that Area = a $x$ h? How would you justify this formula?" It is notable that the students successfully found that the area of a parallelogram is "base $x$ height" based on the area relation of a rectangular. Only one student $\left(\mathrm{P}_{1}\right)$ failed to provide any justification for the area formula although $\mathrm{s} /$ he knew the area relation. The students who justified the formula dissected the parallelogram into a rectangle (See. Figure 4). The quote from $\mathrm{P}_{2}$ would best explain this finding:

R: How do you conclude that the area of a parallelogram is base times height?

$\mathrm{P}_{2}$ : Well, when we count unit squares and find the area for the rectangle, the result will be the same for the area for the parallelogram.

R: Could you please show how it will be the same?

$\mathrm{P}_{2}$ : When we put that to the opposite side... I first count the squares and then place the edges there.

R: How do you place what?

$\mathrm{P}_{2}$ : There, to make this flat, we put this triangle there and form a rectangle. When we take this piece out of here and put it here, we form a full rectangle.

Figure 4

The answer of $P_{2}$ for confirming the area formula for a parallelogram

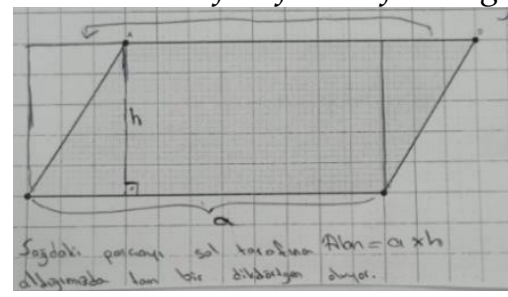

Another important finding regarding this category is that the students constructed the area relation of a parallelogram based on the area of a rectangle, but they failed to develop the understanding that "a rectangle is a parallelogram." Some students even wrongly believed that "a parallelogram is a rectangle." In this regard, although the students developed the area formula for a parallelogram, they had a hard time in establishing the hierarchical relationship between a rectangle and a parallelogram and failed to reason about the classification of quadrilaterals. 


\subsubsection{Findings on the category of using appropriate measurement techniques}

Table 10 presents the codes identified in the category of using appropriate measurement techniques for circumference, area and volume calculations as well as the frequency values for these codes.

Table 10

Codes identified in the category of using appropriate measurement techniques and the frequency values for these codes

\begin{tabular}{|c|c|c|c|}
\hline \multirow{6}{*}{ 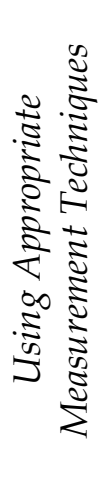 } & Codes & $f$ & Participants \\
\hline & $\begin{array}{l}\text { Using formulas for circumference, area and volume } \\
\text { measurement }\end{array}$ & 12 & $\mathrm{P}_{1}, \mathrm{P}_{2}, \mathrm{P}_{3}, \mathrm{P}_{4}, \mathrm{P}_{6}$ \\
\hline & $\begin{array}{l}\text { Using tools (e.g. meter, ruler, book, etc.) for } \\
\text { circumference, area and volume measurement }\end{array}$ & 11 & $\mathrm{P}_{1}, \mathrm{P}_{2,} \mathrm{P}_{4}, \mathrm{P}_{5}$ \\
\hline & $\begin{array}{l}\text { Making estimates for circumference, area and volume } \\
\text { measurement }\end{array}$ & 10 & $\mathrm{P}_{1}, \mathrm{P}_{2}, \mathrm{P}_{3}, \mathrm{P}_{4}, \mathrm{P}_{5}, \mathrm{P}_{6}$ \\
\hline & Systematic counting for area measurement & 5 & $\mathrm{P}_{1}, \mathrm{P}_{2}, \mathrm{P}_{3}$ \\
\hline & $\begin{array}{l}\text { Counting unit squares, covering/filling with unit squares } \\
\text { for area measurement }\end{array}$ & 2 & $\mathrm{P}_{2,} \mathrm{P}_{6}$ \\
\hline
\end{tabular}

Table 10 indicates that the students mostly used the strategy of "using formulas" $(\mathrm{f}=12)$ to calculate circumference, area and volume. It is interesting that the students primarily opted for using formulas particularly in area measurement and did not benefit from the strategy of "counting unit squares, covering/filling with unit squares for area measurement" $(\mathrm{f}=2)$ much. To compare the areas of different rectangles, the students were engaged with systematic counting through unit squares to calculate the area of each rectangle, then reached the conclusion by multiplying the short and long edges of the quadrilaterals based on the area formula. It seems that this situation limits students from covering/filling a certain area with unit squares to construct the concept of area and from developing the understanding that area refers to the number of unit squares in an area. Because the students had a hard time in defining the concept of area although they successfully calculated the given areas in the interviews. This is also the case for the concept of volume. Therefore, the emphasis of the students on using formulas in measurement seems to restrict them from developing a deep understanding of the concepts of measurement. Figure 5 presents a quote from $\mathrm{P}_{1}$ regarding the use of systematic counting strategy for area measurement.

Figure 5

Systematic counting strategy used by $P_{1}$ for area measurement
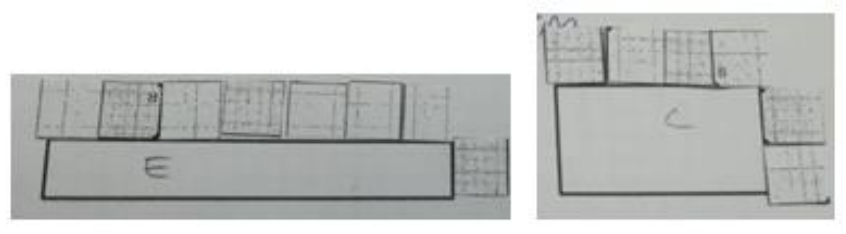

Figure 5 shows that $\mathrm{P}_{1}$ first calculated the edge lengths of quadrilaterals through systematic counting strategy to calculate the area for rectangular areas, then produced the area by multiplying the edge lengths.

\section{Discussion, Conclusion and Suggestions}

This study researches to analyze the conceptual understanding of the middle school 8th grade students based on big ideas. Accordingly, the findings are discussed under eight different categories. This makes it necessary to discuss the important findings obtained in each category under their respective category. In the interviews, regarding measurable attributes, the students considered measurement as length, width/height measurement as well as area, circumference, 
volume calculation and they failed to define it conceptually. This shows that the perceptions of the students on measurement are primarily based on "making numerical calculations" and thus limited. Indeed, the relevant research (Barrettt, et. al., 2017; Battista, 2007) confirmed that students have a hard time in comprehending the concept of unit in measurement. It is also notable that the students developed misconceptions in defining measurable attributes and they wrongly believed that "area refers to volume" and "volume is the area covered in the earth." The understanding of the students on volume is mostly based on internal volume. One of the reasons for this may be that almost all the solutions of the problems in textbooks and in-class activities benefit from internal volume. Another reason is that volume is generally defined as the area occupied by objects in the space (Çetin et al., 2019). That said, to correct the understanding of the students on the concept of volume, more emphasis needs to be placed on the concepts of different volumes while teaching volume. Also, misconceptions or lack of conceptions of students on volume and area demonstrated that they failed to construct the concept of length measurement conceptually, although they made emphasis on the concept of length in measurement. Because length is key to measurement and area, circumference and volume measurements are based on length measurements. For that reason, students need to construct area and volume measurement based on length. However, the interviews in this study revealed that the students developed misconceptions on area and volume, which were also reflected in their understanding of length measurement. Another significant finding of this study is that the measurement approaches of the students regarding circumference, area and volume were way better than their performances for understanding of these concepts. In other words, though the students were able to calculate area and volume, they had a hard time in defining and describing these concepts. The reason for this may be that students' knowledge of these concepts is limited.

This study also uncovered that "use of non-standard units of measurement" was common among the students and they most highlighted the units of measurement intended to measure length. Using non-standard units of measurement makes it easier for students to focus on the measured attribute during measurement (NCTM, 2000); yet, the limited use of units of measurement that mostly focuses on length measurement would cause students to develop an incomplete understanding of area and volume measurement. As none of the students came up with an idea such as using unit squares and using glass in measuring volume in the interviews. As for comparison in measurement, the students mostly believed that circumference and area are either directly or inversely proportional. From this standpoint, the students expressed that "when circumference increases, area increases", "when circumference decreases, area decreases too" or "when circumference increases, area decreases." Nevertheless, when circumference increases, area increases/decreases or does not change at all. However, the findings clearly showed that the students failed to adequately construct the concept of invariance. This is also the case for comparison of surface area and volume in prisms. A major finding on this is that the students believed that "surface area is the area in contact with the ground." The reason for this misconception may be that the students could not construct the concepts of edge and base. For that reason, it is possible to argue that their misconceptions on certain concepts caused them to have a hard time in reasoning on surface area and volume measurement. In the sub-category of relative comparison, the students most focused on the relationship between width and height of quadrilaterals while comparing the areas of the quadrilaterals with the same or different areas. The students required numbers to compare the shapes with the same area or similar areas, and some students even argued that it was not possible to make any comparison without applying any solution strategy such as using unit squares or folding paper. This means that the students had a limited understanding in relation to relative comparison. The students had a similar approach in volume comparison. Likewise, Sarama and Clements (2009) reported similar findings and stated that students have great difficulty in comparing area and volume.

As for calculating estimation and approximate values in measurement, the opinions of the students were mostly related to dimensional estimation; they did not mention measurement 
estimation or computational estimation. The strategies used by the students for dimensional estimation were repeating units, random estimates, using benchmark, visualization and using prior knowledge, respectively. This study determined that the students sometimes benefited from these estimation strategies separately and sometimes in combination. Another significant finding on estimation is that the students were more successful in with using dimensional estimation strategies in length estimation compared to weight or volume estimation. The reason for this is perhaps that the students were not knowledgeable about how to use estimation strategies for area and volume as they failed to conceptually understand area and volume measurement. In fact, the students mostly made random estimates just by looking at the shapes, did not use different estimation strategies and consider units as a benchmark in area and volume comparison, which supports the argument that they were not knowledgeable. From this standpoint, it is necessary to perform activities of different nature and teach estimation strategies thoroughly in order to allow students to develop estimation strategies. Because, knowledge of estimation strategies helps making better estimation.

One of the most important findings in this study is that the students emphasized the critical properties of the shapes to determine the relationship between geometric shapes, but they failed to reason to classify them. The underlying reason may be that although the students emphasized the critical properties of quadrilaterals in describing them, they reasoned by focusing on visual and non-critical properties of shapes (e.g. long and short edges) in classifying them. Likewise, studies on the classification of geometric shapes (Fujita, 2012; Tsamir et al., 2008; Zaslavsky \& Zodik, 2014) ascertained that students have difficulty in classification as they "reason based on non-critical properties" in determining the hierarchy between geometric shapes (D'Amore \& Ferdino Pinilla, 2006; Frade, 2005). Another major finding of this study is pertaining to students' development and use of formulas in measurement. In the interviews, the students mostly benefited from memorization-based formulas in calculating circumference, area and volume and were confused particularly about circumference and area measurement. The reason for this may be that students failed to construct the concepts of circumference and area and usually used formulas for measurements. That is, students need to make meaningful learning by using materials in differentiating between circumference and area. This study offered some important insights into the comparison of the areas of quadrilaterals with the same/different areas. For this comparison, the students were engaged with systematic counting through unit squares to measure the side lengths of the shapes and then reached the conclusion by multiplying the short and long edges of quadrilaterals. This approach is key to acknowledging the row and column relationship of edges in area measurement (Huang \& Witz, 2013) and conceptually understanding the multiplication operation in the formula for area (Outhred \& Mitchelmore, 2000). However, the students performed the multiplication relation but considered this relation only as a formula and had a hard time in explaining that the formula for area refers to the area covered. It can be argued that the students failed to realize that area measurement actually means counting unit squares or covering/filling with unit squares. Only one student used the strategy of filling through unit squares. Thus, the fact that the students could not define the concept of area while identifying measurable attributes can be justified by the finding that they failed to construct the concept of area conceptually.

This study importantly demonstrated that the students, who knew the volume formula for prisms, could not comprehend the concepts such as base, height and edge. It is also notable that some students overlooked the concept of height in the volume formula, considered edge as base, were confused with the concepts of base, corner, and length and mistook height for base and believed that the surface area of the prism is the area where it is in contact with the ground. This and similar memorization-based understandings or misconceptions on certain concepts prevent students from establishing a relationship between the formula and the real object. Therefore, it seems that this situation will restrict students' further learning. Another major finding of this study is that the students successfully constructed the area relation of a parallelogram, but they 
failed to comprehend that "a parallelogram is a rectangle." Some students even wrongly believed that "a parallelogram is a rectangle." This finding may indicate that the students could not benefit from their reasoning for formula use in determining the hierarchy between geometric shapes.

The findings of this study revealed that the students failed to develop a full understanding of measurement or simply developed misconceptions. Therefore, it is necessary to perform different in-class activities and place more emphasis on these concepts in teaching in order to eliminate the incomplete conceptual understanding of area, circumference and volume measurement. For example, greater emphasis on the concept of volume may be placed on the fact that when one measures the volume of a regular prism, s/he actually measures its internal volume whereas external volume is about measuring the volume of an irregular prism. Besides, it is essential to determine whether the learning area of measurement in textbooks or curricula is presented based on big ideas and if so, which big ideas are highlighted. This will potentially help exploring how students should construct the concepts regarding measurement and the relationship between these concepts. It is further pivotal to determine whether teachers - the ones who implement the educational process- are knowledgeable about these big ideas. Because, knowledge of big ideas among teachers will contribute to the elimination of the incomplete understandings or misconceptions of students.

Acknowledgements. This study is the extended version of an oral presentation presented at the VIIth International Eurasian Educational Research Congress in Ankara, Turkey.

\section{References}

Baroody, A. J., \& Gatzke, M. R. (1991). The estimation of set size by potentially gifted kindergarten-age children. Journal for Research in Mathematics Education, 22, 59-68. https://doi.org/10.2307/749554

Barrett, J. E., Cullen, C. J., Miller, A. L., Eames, C. L., Kara, M., \& Klanderman, D. (2017). Area in the middle and later elementary grades. In J. E. Barrett, D. H. Clements, \& J. Sarama (Ed.), Children's Measurement: A longitudinal study of children's knowledge and learning of length, area, and volume (pp. 105-127). National Council of Teachers of Mathematics.

Battista, M. T. (2007). The development of geometric and spatial thinking. In F. K. Lester (Ed.), Second handbook of research on mathematics teaching and learning (pp. 843-908). Information Age Publishing.

Budak, M., \& Okur, M. (2012). Teacher views about curriculum of 2005 elementary level mathematic course 6-8. classes. International Journal of New Trends in Arts, Sports \& Science Education, 1(4), 8-22.

Charles, R. (2005). Big ideas and understandings as the foundation for elementary and middle school mathematics. Journal of Education Leadership, 7(3), 9-24.

Charles, R.I., \& Carmel, C.A. (2005). Big ideas and understanding as the foundation for elementary and middle school mathematics. Journal of Mathematics Education Leadership, 7(3), 9-24.

Common Core State Standards Initiative [CCSSI] (2010). Common Core State Standards Initiative: Preparing America's students for college and career. Retrieved from http://www.corestandards.org/

Creswell, J.W. (2013). Qualitative research method (3rd Edition). Sage.

Çetin, Ö., Aksakal, U., Ertürk, Ü., Şay, G., \& Tığlı, İ. (2019). Ortaokul ve imam hatip ortaokulu matematik 8 ders kitabı [Middle school mathematics 8th grade textbook] (1st Edition). MoNE Publishing.

D'Amore, B., \& Fandiño Pinilla, M. I. (2006). Relationships between area and perimeter: Beliefs of teachers and students. Mediterranean journal for research in mathematics education. Mediterranean Journal for Research in Mathematics Education, 5(2), 1-29.

Dowker, A. (1992). Computational estimation strategies of professional mathematicians. Journal for Research in Mathematics Education, 23(1), 45-55. https://doi.org/10.5951/jresematheduc.23.1.0045

Frade, C. (2005). The tacit-explicit nature of students' knowledge: A case study on area measurement. In Chick, H. L. \& Vincent, J. L. (Eds.). Proceedings of the 29 th Conference of the International Group for the Psychology of Mathematics Education (Vol. 2), pp. 321-328. PME.

Fujita, T. (2012). Learners' level of understanding of the inclusion relations of quadrilaterals and prototype phenomenon. The Journal of Mathematical Behavior, 31, 60-72. https://doi.org/10.1016/j.jmathb.2011.08.003

Gough, J. (2008). Fixing misconceptions: Length, area and volume. Australian Mathematics Teacher, 64(2), 3435. 
Gökkurt, B. (2014). An examination of secondary school mathematics teachers' pedagogical content knowledge on geometric shapes. [Unpublished doctoral dissertation]. Atatürk University.

Hanson, S. A. \& Hogan, T. P. (2000). Computational estimation skills of college students. Journal for Research in Mathematics Education, 31(4), 483-499. https://doi.org/10.2307/749654

Hershkowitz, R. (1990). Psychological Aspects of Learning Geometry. In P. Nesher, \& J. Kilpatrick (Eds.), Mathematics and cognition: a research synthesis by the international group for the psychology of mathematics education (pp. 70-95). Cambridge University Press.

Hiebert, J., \& Carpenter, T. P. (1992). Learning and teaching with understanding. In D. A. Grouws (Eds.), Handbook of Research on Mathematics Teaching and Learning (pp. 65-98). Macmillan.

Huang, H. M. E., \& Witz, K. G. (2013). Children's conceptions of area measurement and their strategies for solving area measurement problems. Journal of Curriculum and Teaching, 2(1), 10-26. https://doi.org10.5430/jct.v2n1p10

Kayhan, H., C., \& Argün., C. (2011). The relationship between primary school students' knowledge about the length measurement tools and their usage. Journal of Gazi Education Faculty, 31(2), 479-496. https://doi.org/10.17152/gefd.37779

Kenney, P. A. \& Kouba, V. L. (1997). What do students know about measurement? In P. A. Kenney \& E. A. Silver (Eds.), Results from the Sixth Mathematics Assessment of the National Assessment of Educational Progress (pp. 141-163). Reston, VA: National Council of Teachers of Mathematics.

Kidman, G., \& Cooper, T. J. (1997). Area integration rules for grades 4, 6 and 8 students. In E. Pehkonen (Ed.), Proceedings of the 21st International Conference for the Psychology of Mathematics Education (pp. 136143). Lahti.

Kim, E. M., Haberstroh, J., Peters, S., Howell, H., \& Oláh, L. N. (2019). Elementary students' understanding of geometrical measurement in three dimensions (Research Report No. RR-19-14). Educational Testing Service. https://doi.org/10.1002/ets2.12250

Lee, H. J. (2012). Learning measurement with Interactive Stations. Ohio Journal of School Mathematics, 65, 3036.

Markman, E. M., \& Wachtel, G.F. (1988). Children's use of mutual exclusivity to constrain the meaning of words. Cognitive Psychology, 20, 121-157. https://doi.org/10.1016/0010-0285(88)90017-5

Marks, R. (1990). Pedagogical content knowledge: From a mathematical case to a modified conception. Journal of Teacher Education, 41(3), 3-11. https:/ / doi.org/10.1177/002248719004100302

Mcmillan, H. J. \& Schumacher, S. (2010). Research in education. Boston, USA: Pearson.

Merriam, S. B. (2018). Qualitative research. A guide to design and implementation. Jossey-Bass.

Micklo, S. J. (1999). Estimation It's more than a guess. Childhood Education, 75(3), 142-145. https://doi.org/10.1080/00094056.1999.10522001

Miles, M, B. \& Huberman, A. M. (1994). Qualitative data analysis: An expanded sourcebook. (2nd Edition). Sage.

Ministry of National Education [MONE] (2018). Matematik dersi öğretim programı [Mathematics lesson curriculum] (1, 2, 3, 4, 5, 6, 7 and 8. Class]. MoNE Publishing.

Moreira, C. Q. \& Contente, M. do R. (1997). The role of writing to foster pupil's learning about area. In Pehkonen, E. (Eds.), Proceedings of the Conference of the International Group for the Psychology of Mathematics Education (21st PME, Lahti, Finland), 3, 256-263.

National Council of Teachers of Mathematics [NCTM]. (2000). Principles and standards for school mathematics. Reston, VA: NCTM.

National Council of Teachers of Mathematics [NCTM]. (2005). Principles and standards for school mathematics. Reston, VA: NCTM.

Outhred, L. N., \& Mitchelmore, M. C. (2000). Young children's intuitive understanding of rectangular area measurement. Journal for Research in Mathematics Education, 31, 144-167. https://doi.org/10.2307/749749

Sarama, J. \& Clements, D. H. (2009). Early childhood mathematics education research: Learning trajectories for young children. Routledge.

Schifter, D., \& Fosnot, C. T. (1993). Reconstructing mathematics education: Stories of teachers meeting the challenges of reform. Teachers College Press.

Segovia, I., \& Castro, E. (2009). Computational and measurement estimation; curriculum foundations and research carried out at the university of Granada. Electronic Journal of Research in and Educational Psychology, 17(7), 499-536.

Siemon, D., Bleckly, J., \& Neal, D. (2012). Working with the big ideas in number and the australian curriculum: mathematics. In B. Atweh, M. Goos, R. Jorgensen \& D. Siemon, (Eds.), Engaging the Australian 
National Curriculum: Mathematics - Perspectives From the Field (pp. 19-45). Online Publication of Mathematics Education Research Group of Australasia.

Sowder, J. (1992). Estimation and number sense. In D. A. Grouws (Ed.), Handbook of Research on Mathematics Teaching and Learning (pp. 371-389). Macmillan.

Yin, R. K. (2013). Case study research: Design and methods. SAGE.

Thompson, T. D. \& Preston, R. V. (2004). Measurement in the middle grades: Insights from NAEP and TIMSS. Mathematics Teaching in the Middle School, 9(9), 514-519. https://doi.org/10.5951/MTMS.9.9.0514

Tout, D., \& Spithill, J. (2015). The challenges and complexities of writing items to test mathematical literacy. In K. Stacey \& R. Turner (Eds.), Assessing mathematical literacy: The PISA experience (pp. 145-171). Springer International Publishing.

Tsamir, P., Tirosh, D., \& Levenson, E. (2008). Intuitive nonexamples: the case of triangles. Educational Studies in Mathematics, 69(2), 81-95. https://doi.org/10.1007/s10649-008-9133-5

Van de Walle, J. A., Karp, K.S. \& Bay-Williams, J. M. (2014). Elementary and middle school mathematics: Teaching develop - mentally. Pearson.

Van Hiele, P. (1986). Structure and insight: a theory of mathematics education. Academi Press.

Zaslavsky, O., \& Zodik, I. (2014). Example-generation as indicator and catalyst of mathematical and pedagogical understandings. Y. Li, E. A. Silver., \& S. Li (Eds.), Transforming mathematics instruction: Multiple approaches and practices (pp. 525-546). Springer International Publishing. 